\title{
Personality traits and common psychiatric conditions in patients with seborrheic dermatitis
}

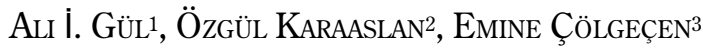 \\ 1 Department of Psychiatry, Bozok University Medical Faculty. \\ 2 Department of Psychiatry, Bozok University Medical Faculty. \\ ${ }_{3}^{3}$ Department of Dermathology, Bozok University Medical Faculty. \\ Institution where the study was conducted: Bozok University Medical Faculty, Research and Training Hospital, Yozgat/Turkey.
}

Received: 4/14/2016 - Accepted: 1/16/2017

DOI: 10.1590/0101-60830000000106

\begin{abstract}
Background: Seborrheic dermatitis is a skin disease in which psychological factors play a central role in its onset, exacerbation and remission. Objective: The aim of this study was to investigate personality traits and common psychiatric conditions in patients with SD. Methods: Outpatients who were admitted to the Bozok School of Medicine Department of Dermatology complaining of SD and who volunteered for study were included. Symptom Checklist 90 - Revised (SCL-90-R) and Eysenck Personality Questionnaire - Revised Short Form (EPQ-RSF) were administered before treatment to 50 patients who fulfilled the criteria for inclusion in the study. Results compiled from the 50 subjects were compared to a control group that was comprised of 50 healthy volunteers. Results: Of the 50 patients that were included in the study, 25 were female and 25 were male. The Global Symptom Index (GSI; Z = -6.96, P $<0.001$ ), Somatization $(Z=-6.59, P<0.001)$, Depression $(Z=-7.11, P<0.001)$, and Anxiety $(Z=-6.64, P<0.001)$ subscales of the SCL-90- $R$ were evaluated. Statistically significantly higher scores were obtained from patients with SD in comparison with the control group on all of these subscales. In addition, the EPQ-RSF Neuroticism subscale was statistically significantly higher $(\mathrm{Z}=-4.99, \mathrm{P}<0.001)$ in patients with $\mathrm{SD}$. Discussion: Our results showed that common psychiatric conditions are considerably frequent in SD patients. More importantly, neurotic personality characteristics were much more frequent in these patients. These findings suggest SD to be a psychosomatic disorder that requires a multi-disciplinary approach.
\end{abstract}

Gül Aİ et al. / Arch Clin Psychiatry. 2017;44(1):6-9

Keywords: Seborrheic dermatitis, somatization, depression, anxiety, neuroticism.

\section{Introduction}

Seborrheic dermatitis (SD) is a common, recurrent disease with chronic progression that affects seborrheic areas, such as skin in regions of the chest presternal area, face, nasolabial area and scalp ${ }^{1}$. SD is usually known as "bran" among adolescents and adults'. This chronic inflammatory skin disease is characterized by yellowish, oily appearing, erythematous, squamous plaques³.

$\mathrm{SD}$ is more common in females and affects more than $1 \%$ to $3 \%$ of the adult population ${ }^{4}$ SD is likely more frequent in infants because of androgen transfer from mothers to infants in the first 3 months of life. SD is also quite frequent in adolescents and adults, with increasing frequency among individuals $>50$ years old 5 .

$\mathrm{SD}$, a multifactorial medical condition, is a disease whose etiology is not yet fully understood. Stress, fatigue, androgens, microangiopathic vascular changes, seasonal atmospheric changes, dietary patterns, nutritional allergies, autoimmunity, Malassezia infections, riboflavin, pyridoxine, and biotin deficiencies play a role in its etiopathogenesis and affect disease severity ${ }^{6}$ SD prevalence is increased by emotional stress, fatigue and depressive conditions ${ }^{7}$.

The central nervous system (CNS) and skin are related due to their embryological origins; thus, some hormones, neurotransmitters and receptors are common to both. Skin is a key sensory organ that plays a role in social interactions throughout the lifetime. Skin reacts to emotional stimuli, and skin appearance affects body image and self-esteem ${ }^{8}$.

A probable relationship was recently reported between some personality traits and skin diseases; however, no study of personality traits in SD patients has been published. Thus, the aim of our study was to investigate the relationship between SD and common psychiatric disorders as well as basic personality traits in SD patients.

\section{Material and methods}

All volunteers who participated in the study were informed according to the Declaration of Helsinki. Institutional Ethics Committee approval was obtained from the Bozok University Medical School Ethics Committee on Non-Interventional Clinical Investigations.

\section{Patients (sample)}

The sample in this study consisted of a total of 50 patients ( 25 females and 25 males) who were admitted to the dermatology clinic and were diagnosed with 'seborrheic dermatitis'. All physical inspections were made by the same dermatologist with an experience of more than 10 years and working as an assistant professor at our university. Age distribution of the patients was $18-66$ years, and the mean age of patients was $26.82 \pm 10.21$ years. The control group consisted of 50 healthy volunteers without a known clinical disease (21 males and 29 females). The mean age of the control group was $29.00 \pm 8.71$ years, and the age range was $19-58$ years. Exclusion criteria were: (1) presence of comorbidities, such as neurological, psychiatric, or medical diseases, (2) alcohol and/or substance abuse, and (3) use of medications (e.g., retinoids) that could cause psychiatric disease.

\section{Data collection and scales}

\section{Demographic data form}

This form was developed by the authors, and was used to obtain demographic data, such as age, gender, educational status, marital status. 


\section{Symptom Check List-90-Revised (SCL-90-R)}

The SCL-90-R was developed by Derogatis9. The validity and reliability of the Turkish translation of this questionnaire were demonstrated by Dağ ${ }^{10}$. The SCL-90-R is a self-evaluation scale used as a psychiatric screening tool to measure the level of psychiatric symptoms and negative stress reactions experienced by an individual. It is used in patient populations older than 17 years of age who have completed a high school education.

It does not have a time limit, and consists of 90 items that are grouped into five Likert-type items. Each item is evaluated according to the "None / Very Little / Moderate / Much / Very Much" scale and given a score of $0,1,2,3$, or 4 . Three separate total scores can be calculated. (1) The Global Symptom Index (GSI) is the general mean score of this measure. An increase in GSI reflects an individual's discomfort caused by psychiatric symptoms, and is the best index of this measure. It is rated from $0-4$ points. A cut-off score of 1.0 point is frequently recommended. It also has nine separate sub-scales that measure psychiatric disorder symptoms of: (1) Somatization, (2) Obsessive - compulsive symptoms, (3) Inter-personal sensitivity, (4) Depression, (5) Anxiety, (6) Enmity, (7) Phobic anxiety, (8) Paranoid ideation, and (9) Psychoticism and other additional scales.

\section{Eysenck Personality Questionnaire - Revised Short Form (EPQ-RSF)}

This measure was developed by Francis et al. ${ }^{11}$. It was adapted to Turkish by Karanci et al., and its validity and reliability were shown by the same authors ${ }^{12}$.

The EPQ is a self-assessment scale used to measure neuroticism, extraversion and psychoticism dimensions of personality, according to the personality concept of Eysenck. It characterizes the personality profiles of various psychiatric patient groups and healthy individuals. It consists of a total of 24 items and four subscales containing six items. The subscales include measurements of neuroticism, extraversion, psychoticism and lying. The participant is required to quickly respond with "yes" or "no", with "1" point given for a "yes" and "0" points for a "no". Every subscale is rated between $0-6$ points. No cut-off value is calculated, but this may be utilized in comparison studies.

\section{Application}

Demographic and clinical data obtained from the patient and control groups were recorded on demographic data forms that were developed by the authors. An academic dermatologist diagnosed patients with SD. SCL-90-R and EPQ-RSF tests were applied to every participant (i.e., patients and controls fulfilling the study inclusion criteria).

\section{Statistical analysis}

Statistical analyses were performed with SPSS version 17 (SPSS Inc., Chicago, IL, USA). Descriptive statistics are presented as means and standard deviation (SD). The SCL-90-R and EPQ-RSF scores were not normally distributed, and thus patient and control group variables were compared using a Mann-Whitney U test. A value of $\mathrm{P}<0.05$ was considered to indicate statistical significance.

\section{Results}

SD location: on the face in 4 patients, on the scalp in 30 patients, and diffuse in 16 patients. Patient mean age was $26.82 \pm 10.21$ years, and control mean age was $29.00 \pm 8.71$ years. Educational status of patients was: primary school, 9; high school, 26; and college, 15. Educational status of controls was: primary school, 7; high school, 22; and college, 21. Eighteen of the patients were married, and 32 were bachelors; 22 individuals in the control group were married, 27 were bachelors and 1 was divorced. Demographic data were not statistically significantly different between the two groups (Table 1).

The SCL-90-R and EPQ-RSF scores of patients and controls are shown with means, standard deviations and medians in Table 2. The SCL-90-R GSI scores $(Z=-6.96, P<0.001)$, somatization scores $(Z=-6.59, P<0.001)$, depression scores $(Z=-7.11, P<0.001)$, and anxiety scores $(Z=-6.64, P<0.001)$ were significantly higher, as was the EPQ-RSF neuroticism subscale score $(Z=-4.99, P<0.001)$ in patients with SD (Figure 1). There was no significant difference between SD patients and the control group in terms of extraversion $(\mathrm{Z}=-1.14, \mathrm{P}=0.25)$. The EPQ-RSF psychoticism subscale score $(Z=-2.11, P<0.05)$ was statistically significantly higher in the control group than in patients with SD (Table 2, Figure 2).

Table 1. Socio-demographic characteristics of groups

\begin{tabular}{|l|c|c|c|}
\hline & $\begin{array}{c}\text { Seborrheic } \\
\text { dermatitis }\end{array}$ & Control & P \\
\hline Gender & & & \\
\hline Male & 25 & 21 & \\
\hline Female & 25 & 29 & \\
\hline Education & & & \\
\hline Primary school & 9 & 7 & 0.073 \\
\hline High school & 26 & 22 & \\
\hline College & 15 & 21 & \\
\hline Mariage & & & \\
\hline Married & 18 & 22 & \\
\hline Single & 32 & 27 & \\
\hline Divorce & 0 & 1 & \\
\hline Age (year) & & & \\
\hline Mean \pm SD & $26.82 \pm 10.21$ & $29.00 \pm 8.71$ & 0.286 \\
\hline
\end{tabular}

Table 2. Statistical comparison of the groups

\begin{tabular}{|c|c|c|c|c|}
\hline & $\mathrm{M} \pm \mathrm{SD}$ & Median & $\mathrm{Z}^{*}$ & $\mathrm{P}^{*}$ \\
\hline SCL-90-R-GSI & & & & \\
\hline Seborrhoic Der. & $1.30 \pm 0.65$ & 1.08 & -6.96 & $<0.001$ \\
\hline Control & $0.39 \pm 0.49$ & 0.20 & & \\
\hline SCL-90-R-Anxiety & & & & \\
\hline Seborrhoic Der. & $1.07 \pm 0.63$ & 0.90 & -6.64 & $<0.001$ \\
\hline Control & $0.34 \pm 0.40$ & 0.20 & & \\
\hline SCL-90-R-Depress & & & & $<0.001$ \\
\hline Seborrhoic Der. & $1.44 \pm 0.70$ & 1.22 & -7.11 & \\
\hline Control & $0.37 \pm 0.53$ & 0.23 & & $<0.25$ \\
\hline SCL-90-R-Somat. & & & & \\
\hline Seborrhoic Der. & $1.34 \pm 0.70$ & 1.02 & -6.59 & $<0.01$ \\
\hline Control & $0.47 \pm 0.48$ & 0.36 & & \\
\hline Eysenck-Neur & & & & \\
\hline Seborrhoic Der. & $3.86 \pm 1.45$ & 4.00 & -4.99 & $<001$ \\
\hline Control & $2.12 \pm 1.28$ & 2.00 & & \\
\hline Eysenck-Extr. & & & & \\
\hline Seborrhoic Der. & $2.62 \pm 1.21$ & 3.00 & & \\
\hline Control & $2.97 \pm 1.14$ & 3.00 & & \\
\hline Eysenck-psik. & & & & \\
\hline Seborrhoic Der. & $2.30 \pm 0.70$ & 2.00 & & \\
\hline Control & $2.65 \pm 0.94$ & 3.00 & & \\
\hline SHU Tet. & & & \\
\hline
\end{tabular}

* MWU Test. 


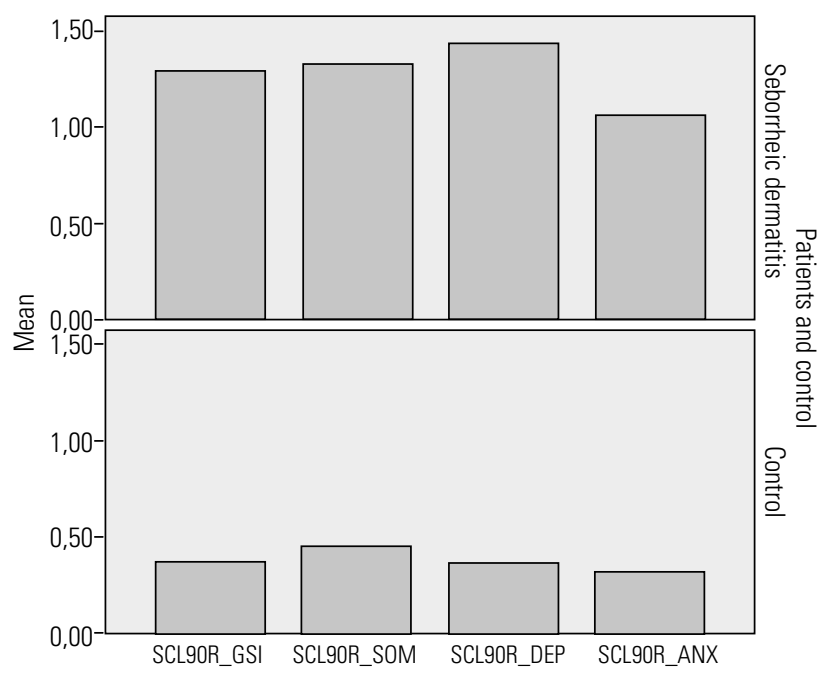

Figure 1. The SCL-90-R GSI scores, somatization scores, depression scores, and anxiety scores were significantly higher in patients with seborrheic dermatitis.

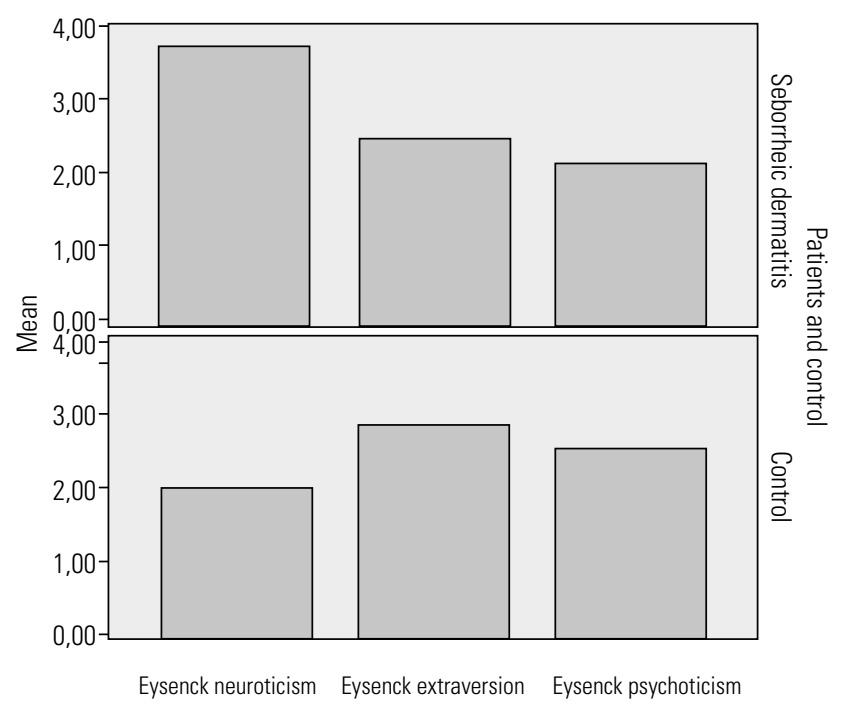

Figure 2. Comparison of Eysenck Personality Questionnaire - neuroticism, extraversion and psychoticism subscales in patients with seborrheic dermatitis and the control group.

\section{Discussion}

It is widely believed that psychological stress, some personality traits, and psychiatric disorder complications are related to, and manifest as skin disease ${ }^{13}$. Thus, in the current study, the SCL90-R was used to investigate common psychiatric symptoms in SD patients. SCL-90-R subscales (i.e., GSI, somatization, depression and anxiety) were evaluated. These subscale scores were statistically significantly higher among SD patients than in individuals in the control group.

The relationship between SD and quality of life has been investigated extensively recently. The negative effects of the disease on quality of life are more frequently found in younger, more highly educated, and female patients ${ }^{14}$. Some researchers highlight the negative effect of SD on quality of life, and propose that this skin disease may increase an individual's vulnerability to developing depression ${ }^{15}$. A multicenter epidemiological study by Peyrí et al. showed that quality of life in SD patients was more negatively affected in younger and female patients who had a more severe form of the disease. A relationship existed between the time of disease manifestation and anxiety/stress in most SD patients ${ }^{16}$. Another study showed that impaired quality of life in SD patients affected an increase in anxiety-depression scores ${ }^{17}$.

$\mathrm{SD}$ is observed in patients with common neurological diseases, such as Parkinson's disease, poliomyelitis, epilepsy, quadriplegia, and syringomyelia ${ }^{18}$. Mastrolonardo et al. highlighted the relationship between Parkinsonism and SD, and described the occurrence of increased sebum extraction in Parkinson's disease ${ }^{18}$. SD occurrence was reportedly linked to neuroleptic drug-induced Parkinsonism in a study of schizophrenia patients ${ }^{19}$. Another study investigated how impaired quality of life in SD patients and impairment severity contributed to individuals developing high rates of anxiety and depression ${ }^{20}$.

SD prevalence was studied in 150 patients with severe schizophrenia, mood disorders, anxiety disorders and organic mental disorders. SD was diagnosed in 38 patients, and these data was statistically significant ${ }^{21}$. In our study, high SCL-90-R somatization subscale scores in SD patients were statistically significantly different from the control group. In a study performed with musicians, Önder et al. highlighted the concept that many dermatological diseases were related to stress ${ }^{22}$. Alexithymia and difficulties in verbal extraversion of emotions were found in a study with psoriasis patients ${ }^{23}$, but a related study involving SD patients was not found among the literature.

SD patient EPQ-RSF-neuroticism subscale scores were statistically significantly higher than control group scores. The strongest and most unique predictor of common psychiatric disorders is neuroticism, which plays an important role in persistent, low subjective well being and psychological stress-linked physical health problems ${ }^{24}$.

\section{Conclusions}

We found statistically significantly higher rates of depression and anxiety in SD patients compared with the control group in the present study. In addition, significantly more somatization and neurotic personality trait properties were found among these patients. These data show that SD patients are likely to somatize their emotions. This reflects a probable reciprocal relationship between SD, personality traits and psychological stress. However, our study has some limitations. Larger longitudinal studies are necessary to further assess this link. Another, a structured interview for psychiactric diagnoses (such as the SCID) has not been employed in our study, either to confirm psychiatric comorbidities in SD patients or to rule out psychiatric conditions in the healthy control group.

Another important aspect of our study is that it demonstrates the high frequency of concomitant dermatological diseases and psychiatric disorders observed in clinical practice, and thus why $\mathrm{SD}$ is considered by some authors to be a psychosomatic disorder. Treatment plans for these kinds of diseases should employ a multidisciplinary approach, which would benefit both treatment outcomes and financial aspects.

\section{References}

1. Gupta AK, Bluhm R. Seborrheic dermatitis. J Eur Acad Dermatol Venereol. 2004;18(1):13-26.

2. Goldust M, Rezaee E, Raghifar R, Hemayat S. Treatment of seborrheic dermatitis: the efficiency of sertaconazole $2 \%$ cream vs. tacrolimus $0.03 \%$ cream. Ann Parasitol. 2013;59(2):73-7.

3. Misery L, Touboul S, Vincot C, Dutray S, Rolland-Jacob G. Stress and seborrheic dermatitis. Ann Dermatol Venereol. 2007;134(11):833-7. 
4. Emre S, Metin A, Demirseren DD, Akoglu G, Oztekin A, Neselioglu S, et al. The association of oxidative stress and disease activity in seborrheic dermatitis. Arch Dermatol Res. 2012;304(9):683-7.

5. Palamaras I, Kyriakis KP, Stavrianeas NG. Seborrheic dermatitis: lifetime detection rates. J Eur Acad Dermatol Venereol. 2012;26(4):524-6.

6. Ro BI, Dawson TL. The role of sebaceous gland activity and scalp microfloral metabolism in the etiology of seborrheic dermatitis and dandruff. J Investig Dermatol Symp Proc. 2005;10(3):194-7.

7. Picardi A, Abeni D. Stressful life events and skin diseases: disentangling evidence from myth. Psychother Psychosom. 2001;70(3):118-36.

8. Picardi A, Porcelli P, Pasquini P, Fassone G, Mazzotti E, Lega I, et al. Integration of multiple criteria for psychosomatic assessment of dermatological patients. Psychosomatics. 2006;47(2):122-8.

9. Derogatis LR. SCL-90: Administration, scoring and procedure manual-1 for the revised version. Baltimore, 1977.

10. Dağ İ. Belirti Tarama Listesi (SCL-90-R)' nin üniversite öğrencileri için güvenilirliği ve geçerliliği. Turk J Psychiatry. 1991;2(1):5-12.

11. Francis LJ, Brown LB, Philipchalk R. The development of an abbreviated form of the Revised Eysenck Personality Questionnaire (EPQR-A): Its use among students in England, Canada, the USA and Australia. Pers Indiv Diff. 1992;13(4):443-9.

12. Karancı AN, Dirik G, Yorulmaz O. Eysenck Kişilik Anketi-Gözden Geçirilmiş Kısaltılmış Formunun (EKA-GGK) Türkiye'de Geçerlik Ve Güvenilirlilik Çalışması. Turk J Psychiatry. 2007;18(3):254-61.

13. Picardi A, Pasquini P, Cattaruzza MS, Gaetano P, Melchi CF, Baliva G, et al. Stressful life events, social support, attachment security and alexithymia in vitiligo. A case-control study. Psychother Psychosom. 2003;72(3):150-8.

14. Szepietowski JC, Reich A, Wesołowska-Szepietowska E, Baran E; National Quality of Life in Dermatology Group. Quality of life in patients suffering from seborrheic dermatitis: influence of age, gender and education level. Mycoses. 2009;52(4):357-63.
15. Öztaş P, Calıkoğlu E, Cetin İ. Psychiatric tests in seborrhoeic dermatitis. Acta Dermatol Venereol. 2004;85(1):68-9.

16. Peyrí J, Lleonart M; Grupo español del Estudio SEBDERM. Clinical and therapeutic profile and quality of life of patients with seborrheic dermatitis. Actas Dermosifiliogr. 2007;98(7):476-82.

17. Doğramacı AC, Yurtman Havlucu D, Savas N. The evaluation of quality of life of patients with seborrheic dermatitis. Turk J Dermatol. 2008;2(4):99-102.

18. Cowley NC, Farr PM, Shuster S. The permissive effect of sebum in seborrhoeic dermatitis: an explanation of the rash in neurological disorders. Br J Dermatol. 1990;122(1):71-6.

19. Mastrolonardo M, Diaferio A, Logroscino G. Seborrheic dermatitis, increased sebum excretion, and Parkinson's disease: a survey of (im) possible links. Med Hypotheses. 2003;60(6):907-11.

20. Binder RL, Jonelis FJ. Seborrheic dermatitis: a newly reported side effect of neuroleptics. J Clin Psychiatry. 1984;45(3):125-6.

21. Aksoy M, Özkorumak E, Bahadır S, Yaylı S, Arıca DA. Quality of life, anxiety and depression levels in patients with seborrheic dermatitis. Turkderm. 2012;46(1):39-43.

22. Önder M, Coşar B, Öztaş MO, Candansayar S. Stress and skin diseases in musicians. Evaluation of the Beck Depression Scale, General Psychologic Profile (The Brief Symptom Inventory [BSI]), Beck Anxiety Scale and stressful life events in musicians. Biomed Pharmacother. 2000;54(5): 258-62.

23. Ozguven HD, Kundakçı N, Kumbasar H, Boyvat A. The depression, anxiety, life satisfaction and affective expression levels in psoriasis patients. J Eur Acad Dermatol Venereol. 2000;14(4):267-71.

24. Ormel J, Jeronimos BF, Kotov R, Riese H, Bos EH, Hankin B, et al. Neuroticism and common mental disorders: meaning and utility of a complex relationship. Clin Psychol Rev. 2013;33(5):686-97. 